\title{
The Person-in-the-Rain Drawing as a Predictor of Conscript Soldiers' Unit Cohesion
}

\author{
Juliet Jue ${ }^{*}$, Jung Hee Ha², Yoojin Jang² \\ ${ }^{1}$ Department of Art Therapy, Hanyang Cyber University, Seoul, Republic of Korea \\ ${ }^{2}$ Graduate School of Counseling Psychology, Hanyang University, Seoul, Republic of Korea \\ Email: *juliet@hycu.ac.kr
}

How to cite this paper: Jue, J., Ha, J. H., \& Jang, Y. (2020). The Person-in-the-Rain Drawing as a Predictor of Conscript Soldiers' Unit Cohesion. Psychology, 11, 594-605. https://doi.org/10.4236/psych.2020.114040

Received: March 21, 2020

Accepted: April 18, 2020

Published: April 21, 2020

Copyright (c) 2020 by author(s) and Scientific Research Publishing Inc. This work is licensed under the Creative Commons Attribution International License (CC BY 4.0).

http://creativecommons.org/licenses/by/4.0/

\begin{abstract}
We explored the predictive power of the Person-in-the-Rain drawing test (PITR) as an alternative psychological test for understanding and evaluating soldiers' unit cohesion. The participants were 204 conscript soldiers who serve a mandatory military service. They completed the PITR and the Unit Cohesion Scale. We analyzed the data using descriptive statistics, correlation analysis and multiple regression analysis. As a result, the PITR resource score and the coping capacity score correlated positively with unit cohesion. The regression analysis confirmed that the PITR resource score had a statistically significant influence on unit cohesion. This study provides empirical evidence to support the possibility of using PITR as a projection test to predict soldiers' unit cohesion.
\end{abstract}

\section{Keywords}

Person-in-the-Rain, Resource Score, Unit Cohesion, Soldiers

\section{Introduction}

People experience various changes throughout their lives. Rapid changes in the environment can be a great stress, especially when they are inevitable. In Korea, all male adults are obliged to join the military to fulfill the duty of national defense. For conscript soldiers, the army is a stressful environment due to intensive training, the culture of command and discipline, the hierarchical structure, and limited private space, as ordinary soldiers are confined to their barracks (Chun, Chae, \& Lee, 2016; Hong \& Yang, 2013; Lee \& Park, 2012; Lee, Seo, \& Byun, 2016; Seol, 2018). There has been growing interest in predicting soldiers' psychological status due to reports of serious problems in the army, including assaults, firearms accidents, shooting rampages, desertion, suicide, and mental 
disorders (Ahn, Sohn, Lee, \& Seo, 2007; Jung \& Lee, 2008; Kim, 2009).

One of the important variables affecting military life adaptation is unit cohesion (Siebold, 2007; Seol, 2018; Williams et al., 2016). For soldiers who live in barracks, unit cohesion plays an important role not only in overall mental health, but also in achieving individual needs and goals. Unit cohesion occurs during the performance of a group task and is characterized by a willingness to solve problems together in the process of achieving group goals (Wang, Ying, Jiang, \& Klein, 2006). It also implies the ability to build trust and teamwork through relationships between members (Siebold, 2007). Carless and De Paola (2000) classified unit cohesion as social cohesion, task cohesion, and attachment to a group. Social cohesion refers to the degree to which all members are united to form social unity. Task cohesion refers to the degree to which a group is united and committed to achieving a task. Attachment to a group means the extent to which each member has an attachment to the group. The stronger the unit cohesion within the group, the more positive and frequent the social interactions tend to be and the better the individuals' ability to cope in crisis situations; overall adjustment of group members was also shown to improve (Carless \& De Paola, 2000).

The main psychological tests frequently used for soldiers are the Minnesota Multiphasic Personality Inventory, Military Sentence Completion Test, Myers-Briggs Type Indicator, Ego-Ok gram, the Enneagram of Personality test, the house-tree-person test, and the kinetic house-tree-person test (Koo, 2013). Although not included in the list, the person-in-the-rain (PITR) is a projective drawing test to depict psychological factors related to stress and coping capacity. The PITR adds rain to a human figure drawing, and it symbolically shows how one deals with environmental stress (Hammer, 1958; Willis, Joy, \& Kaiser, 2010).

The raining situation depicted in the picture symbolically refers to a stressful environment. Through the coping mechanisms and the portrayal of the person in the picture, it is possible to estimate a test subject's psychological resources, defense mechanisms, and ego strength (Oster \& Gould, 1987; Rossi, 1997; Verinis, Lichtenberg, \& Henrich, 1974). The amount of rain, direction, and strength are interpreted as indicating the amount of subjective stress the subject perceives. Moreover, environmental factors, such as cloudiness and lightning, can add to a subject's interpretation of the picture as a stressful environment. For instance, when a subject perceives the depicted person as lacking equipment to protect themselves, the subject is symbolically indicating a personal unhealthy state.

Previous PITR studies on soldiers have focused on various psychological aspects related to stress and adjustment. Lee and Lee (2014) examined the relationship between the PITR and job stress of occupational soldiers, and reported that the soldiers with higher job stress had significantly higher PITR stress scores and that the soldiers who reported low job stress showed higher PITR resource scores than those of the high-job-stress group. Jue and Ha (2019a) examined army soldiers' perceived stress, stress response and mental health status along with the PITR. They concluded that the PITR could be considered a useful tool 
to examine soldiers' psychological states. Another study examining the relationship between the PITR responses, military life adjustment, and resilience of conscript soldiers showed that PITR resource score and coping capacity score have discriminatory power on the psychological properties (Jue \& Ha, 2019b).

Other researchers studied the PITR among a wide range of study subjects, including teachers, nurses, students, and adolescents (Chung, 2012; Jeong \& Kim, 2008; Jue \& Kim, 2011; Kang \& Lee, 2014; Krom, 2002; Russo, 2007). Most PITR research was performed with psychological factors related to stress, and not a few researchers criticized the weak correlations between the stress response and the PITR (Kim, 2011; Son, 2007; Willis, Joy, \& Kaiser, 2010; Yang \& Won, 2013).

Given the nature of a projection test where unconscious or unacknowledged elements are projected, the PITR test could be related to more complicated psychological property than stress. Therefore, we chose to explore soldiers' unit cohesion as projected in the PITR drawings, because cohesion is influenced not only by thoughts, feelings, and interpersonal relationships, but also by one's own unconscious elements. This study aims to examine the relationship between the PITR and the unit cohesion of conscripted soldiers.

\section{Method}

\subsection{Participants}

The participants consisted of 216 conscripted army soldiers who were serving a mandatory military service. The South Korean military has occupational soldiers and conscript soldiers, and conscript soldiers are men who fulfill the mandatory military service period applicable to all men of the Republic of Korea, typically 20 to 21 months of military service will carry out military service obligations. Around 300,000 conscript soldiers a year enter the military at an average age between 19 and 25 .

We used data on a total of 204 respondents after we excluded 12 respondents who had insincere and unfinished answers. All participants were male, and their mean age was 21.03 years $(\mathrm{SD}=1.40$ years); by marital status, $1.4 \%$ were married and $98.5 \%$ were single. The distribution for education level was as follows: graduated from high school, 18.1\%; enrolled in college, 76.5\%; and graduated from college, $5.4 \%$. The participants reported their socioeconomic status as $5.4 \%$ upper class, $17.2 \%$ upper middle class, $67.2 \%$ middle class, $8.3 \%$ working class, and $2.0 \%$ poor; $1 \%$ did not answer. By location, the men were stationed in rural and mountainous areas $52.9 \%$, metropolitan areas $7.8 \%$, and small towns $39.3 \%$. The duration of duty was 20 months to 21 months depending on the time of conscription, and the average period of service at the time of participation was 11.28 months ( $\mathrm{SD}=5.37$ months).

\subsection{Procedure and Ethical Considerations}

We collected the data for this study after obtaining approval from the army headquarters based on the results of questionnaire security review; participation 
in the survey was entirely voluntary and anonymous. Before starting, the soldiers were provided with the research protocol as a group and informed about the purpose and method of the research, its confidentiality, anonymity, and their rights as participants to refuse or discontinue participation. The soldiers answered the questionnaire in places where the researchers and the unit commanders were absent, placing completed questionnaires. We were the only ones with access to the questionnaire collection box to guarantee the anonymity and spontaneity of the research participants. This research was approved by the institutional review board of Hanyang University, and the IRB approval number was HYI-18-229-1.

\subsection{Measures}

- The person-in-the-rain drawing test. The PITR was developed by Abrams and Amchin (Hammer, 1958); the instruction is simply to draw a person in rain, and the materials include $210 \times 297 \mathrm{~mm}$ white paper, pencils, and erasers. We used the PITR scoring scale developed by Lack (1996) and translated into Korean by Son (2004). There are 35 evaluation items on the stress scale and the resource scale. Most items take a score of 0 or 1 point, but a few are scored according to the number of the corresponding items. For example, the puddle item uses the number of puddles for the score.

The three evaluation scales are the Stress Score (SS), the Resource Score (RS), and the Coping Capacity Score (CCS). The coping capacity score (CCS) is calculated by subtracting the SS from the RS. The higher the SS, the more stressed the person is in the rain, and the higher the RS, the more resources the subject has for coping with stress. The CCS estimates the subject's coping ability in a stressful situation. In this study, scoring was performed by two art therapists. The interrater reliability was $0.92-1.00$.

- The Unit Cohesion Scale. The unit cohesion scale (UCS) was developed by Lee (2006) based on Carless and De Paola' questionnaire (2000). It is composed of 12 items with four items per sub-scale: social cohesion, task cohesion, and attachment to unit. It is rated on a five-point Likert scale. Lee (2006) reported the Cronbach's $\alpha$ as $0.80-0.84$. In this study, we found that the Cronbach's a was 0.86 .

\subsection{Analysis}

Data were analyzed using IBM SPSS 25.0. The frequency and percentage of the general characteristics of the participants were determined. We performed descriptive statistics, correlation analysis and regression analysis to investigate the relationship between the PITR and unit cohesion.

\section{Results}

\subsection{Descriptive Statistics}

Table 1 shows the descriptive statistics for PITR, UCS, and four demographic 
factors including age, educational level, socioeconomic status, and service period at the time of participation for the 204 soldiers who participated in the study. The mean SS score was $5.06(\mathrm{SD}=1.92)$ and the mean RS score was $2.94(\mathrm{SD}=$ 4.64). The CCS score, which we calculated by subtracting the SS from the RS, presented a mean of $-2.12(\mathrm{SD}=5.39)$. The $\mathrm{CCS}$ scores ranged from a minimum of -17.00 to a maximum of 10.00 . The mean UCS score was $3.53(\mathrm{SD}=0.66)$, with the highest mean score among the subscales being for task cohesion. Table 1 also presents the descriptive statistics for the demographic factors. We scored education level from one to three points for statistical processing with higher scores indicating higher levels of education. For socioeconomic status, we scored each category from one to five points according to status level: the higher the score, the higher the status. The mean socioeconomic status score was 3.16 (SD $=0.73)$, which was closest to middle class.

\subsection{Correlation Analysis}

The correlation analysis results are presented in Table 2. The three PITR scores showed significant correlations with one another. The SS correlated negatively with the RS, $r(203)=-0.22, p<0.01$ and also negatively with the CCS, $r(203)=$ $-0.54, p<0.001$. The RS and the CCS showed a very high positive correlation, $r(203)=0.94, p<0.001$.

The unit cohesion scale showed significant correlation with the RS and the CCS, $r(203)=0.23, p<0.01, r(203)=0.21, p<0.01$. The soldiers who felt stronger cohesion to their units expressed more psychological resources and greater coping capacity. The UCS sub-scales, social cohesion, task cohesion, and the attachment to unit, showed significant correlations with the RS and the CCS.

Table 1. Descriptive statistics for PITR, UCS, and demographics.

\begin{tabular}{|c|c|c|c|c|}
\hline Variable & M & S.D. & Minimum & Maximum \\
\hline \multicolumn{5}{|l|}{ Person-In-The-Rain } \\
\hline 1) Stress Score & 5.06 & 1.92 & 0.00 & 14.00 \\
\hline 2) Resource Score & 2.94 & 4.64 & -10.00 & 11.00 \\
\hline 3) Coping Capacity Score & -2.12 & 5.39 & -17.00 & 10.00 \\
\hline Unit Cohesion & 3.53 & 0.66 & 1.09 & 5.00 \\
\hline 1) Social Cohesion & 3.39 & 0.72 & 1.25 & 5.00 \\
\hline 2) Task Cohesion & 3.92 & 0.72 & 1.00 & 5.00 \\
\hline 3) Attachment to Unit & 3.38 & 0.92 & 1.00 & 5.00 \\
\hline \multicolumn{5}{|l|}{ Demographic factors } \\
\hline 1) Age (year) & 20.99 & 1.29 & 19.00 & 27.00 \\
\hline 2) Educational level & 1.87 & 0.47 & 1.00 & 3.00 \\
\hline 3) Socioeconomic status & 3.16 & 0.73 & 1.00 & 5.00 \\
\hline 4) Service period (month) & 11.28 & 5.37 & 1.00 & 20.00 \\
\hline
\end{tabular}


Table 2. Correlations for scores on PITR, unit cohesion, and demographic factors.

\begin{tabular}{ccccc}
\hline Variable & SS & RS & CCS & UCS \\
\hline Person-In-The-Rain & & & & \\
1) Stress Score (SS) & 1 & & & \\
2) Resource Score (RS) & $-0.22^{* *}$ & 1 & & \\
3) Coping Capacity Score (CCS) & $-0.54^{* * *}$ & $0.94^{* * *}$ & 1 & 1 \\
Unit Cohesion (UCS) & -0.04 & $0.23^{* *}$ & $0.21^{* *}$ & \\
1) Social Cohesion & -0.11 & $0.17^{*}$ & $0.18^{* *}$ & \\
2) Task Cohesion & 0.00 & $0.21^{* *}$ & $0.18^{* *}$ & \\
3) Attachment to Unit & 0.02 & $0.21^{* *}$ & $0.17^{*}$ & \\
Demographic factors & & & & -0.02 \\
1) Age (year) & -0.03 & -0.05 & -0.03 & 0.04 \\
2) Educational level & -0.09 & -0.02 & 0.003 & 0.05 \\
3) Socioeconomic status & 0.01 & -0.09 & -0.08 & $-0.16^{*}$ \\
4) Service period (month) & -0.01 & -0.04 & -0.03 &
\end{tabular}

${ }^{*} p<0.05,{ }^{* *} p<0.01,{ }^{* * *} p<0.001$.

\subsection{Multiple Regression Analysis}

To examine the predictive power of the PITR, we performed multiple regression analyses. The unit cohesion was set as the dependent variable, with the PITR and the demographic variables as the independent variables. We used stepwise method-based multiple regression analysis; Table 3 presents the results. The result of a Durbin-Watson test, 2.06, and collinearity diagnostics confirmed no autocorrelation and no multicollinearity.

We found that two independent variables had significant effects: RS $(p<0.01)$ and service period $(p<0.05)$. The unstandardized coefficients indicated that higher RS scores and shorter service periods strengthened unit cohesion. The independent variables explained $8 \%$ of the variation in the dependent variable. We present a scatter plot with a regression line showing the relationship between the RS and unit cohesion in Figure 1.

\subsection{Drawing Examples}

Figure 2 and Figure 3 present examples of participants' PITR drawings. Figure 2 shows a person in heavy rain without holding an umbrella. The rain space is more than 1.5 times larger than the person, and it is certain that the figure would be getting wet from the rain. Although there are no puddles or lightning, an overwhelmingly large dark cloud is present directly over the figure. All of these features were scored in the stress index. There was little that could be regarded as resources for the character. There is an umbrella, but it is not acting as a protector, instead lying on the ground next to the person. There is no indication that the figure is wearing rain gear. The posture of the person is also a backward 
position, so the face is not visible, and the figure is less than two inches in size. These features were calculated as resource scores. The participant that depicted this figure resulted in a unit cohesion score of 3.45. The drawing was scored as $\mathrm{SS}=8.0, \mathrm{RS}=0.0$, and $\mathrm{CCS}=-8.0$.

Table 3. Regression analysis results of PITR and demographics on UCS.

\begin{tabular}{cccccccccc}
\hline \multirow{2}{*}{$\begin{array}{c}\text { Dependent } \\
\text { variable }\end{array}$} & $\begin{array}{c}\text { Independent } \\
\text { variable }\end{array}$ & B & SE & $\beta$ & $t$ & $p$-value & \multicolumn{2}{c}{$\begin{array}{c}\text { Collinearity } \\
\text { diagnostics }\end{array}$} \\
\hline \multirow{2}{*}{ UCS } & (Constant) & 3.64 & 0.11 & & $33.32^{* * *}$ & 0.000 & & \\
& PITR RS & 0.03 & 0.01 & 0.24 & $3.48^{* *}$ & 0.001 & 0.99 & 1.00 \\
& Service period & -0.02 & 0.01 & -0.15 & $-2.25^{*}$ & 0.025 & 0.99 & 1.00
\end{tabular}

$R(0.288), R^{2}(0.083), \Delta R^{2}(0.073), F(8.812), p$-value (0.000), Durbin-Watson (2.06)

Note. $\mathrm{n}=204$, B: unstandardized coefficients, SE: standard error, $\beta$ : standardized coefficients, VIF: Variance Inflation Factor, UCS: Unit cohesion scale, ${ }^{\star} p<0.05,{ }^{* *} p<0.01,{ }^{* *} p<0.001$.

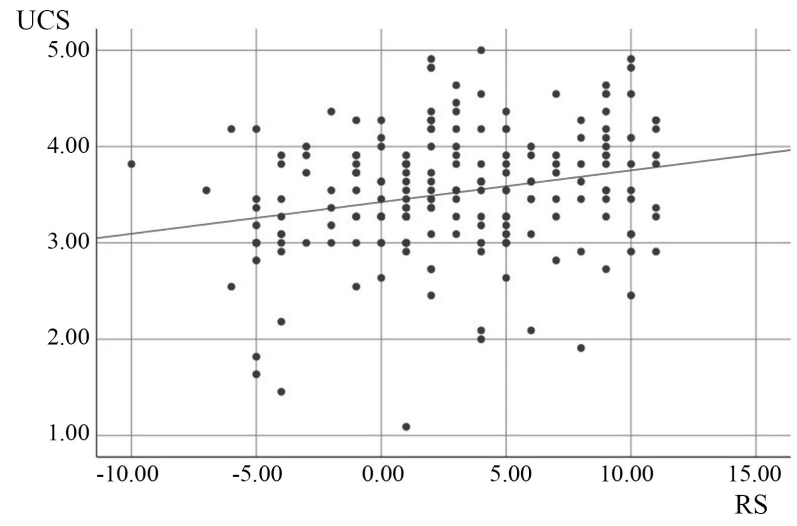

Figure 1. Scatter plot with a fitted regression line of relationship between the resource score (RS) and the unit cohesion (UCS).

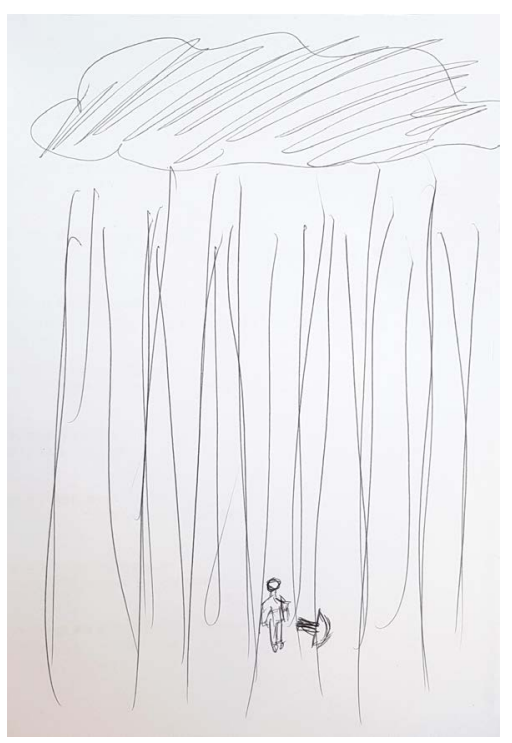

Figure 2. First example of PITR. 


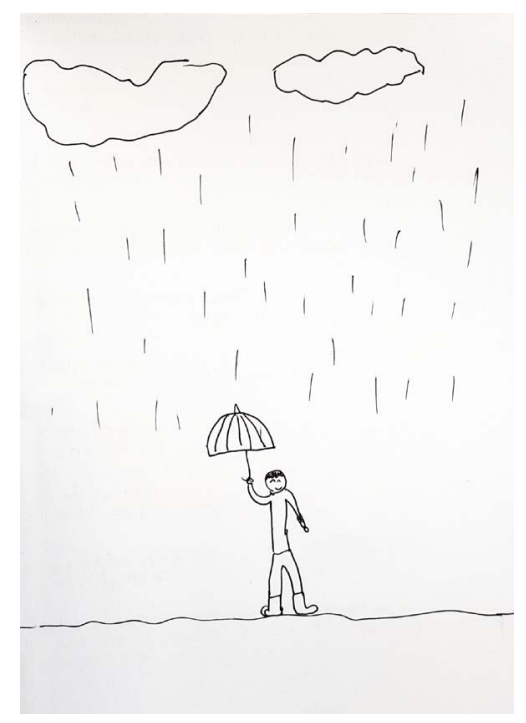

Figure 3. Second example of PITR.

In contrast, a person in Figure 3 is holding an umbrella and wearing boots. Although there are stressors in the picture, including a wide area of rain, two clouds, and a narrow umbrella causing increased likelihood of the figure getting wet from the rain, many pictorial representations of resources are also indicated. For example, the person is holding an umbrella properly and wearing boots and clothes. We can see his full face, which is smiling, and the adequately-sized figure is the center of the paper. Only a few body parts are not present. This participant reported a unit cohesion score of 3.56. The PITR scores included SS = $5.0, \mathrm{RS}=9.0$, and $\mathrm{CCS}=3.0$.

\section{Discussion and Conclusion}

For this study, we explored the relationships between PITR responses and unit cohesion among army soldiers. The participants included 204 army soldiers who were conscripted according to the duty of defense. The results obtained in this study and their implications were compared with previous research findings.

Among the three PITR scores, the Resource Score was the most powerful predictor of unit cohesion. There was a significant correlation between the Coping Capacity Score and unit cohesion, while the Stress Score in this study exhibited no significant correlations with unit cohesion. Previous investigators found similar results indicating that the Stress Score showed lower explanatory power than other PITR scores (Jue \& Ha, 2019b; Kwon, Kim, \& Song, 2016). When examining the relationship between self-efficacy and the PITR among nurses, significant differences were observed in the PITR resource scores according to the amount of self-efficacy, but no difference was found for the PITR stress scores (Kwon, Kim, \& Song, 2016). Jue and Ha (2019b), who conducted the PITR among conscript soldiers, found that soldiers with high military life adjustment showed greater coping capacity and presence of more resources on the PITR, but no differences were observed in the PITR stress scores between the high and low mili- 
tary adjustment groups.

The Coping Capacity Score also showed significant correlation results, specifically, significant correlations with total unit cohesion and all three sub-variables of unit cohesion. Although the CCS was not included in a significant independent variable in regression analysis result because of its high correlation with the RS, it is worth paying attention to the score. The CCS was calculated by subtracting the Stress Score from the Resource Score, and was considered to reflect how efficiently respondents could cope with stressful situations. There are studies describing that the CCS was more important than the other two scores. Jue and Kim's (2011) regression analysis of predictors of high-school girls' delinquency tendencies found that the CCS was the only significant indicator among the three PITR scores. Another study focusing on middle-school students and their academic stress showed that the CCS exhibited the most significant results (Jeong \& Kim, 2008). Kim (2011) added evidence to this phenomenon, examining the relationship between PITR and the stress of vocational high-school students and finding that the CCS correlated with stress levels but the SS did not.

Researchers also administered the PITR before and after group therapy to investigate its effectiveness. Choi and Kim (2009) conducted eight weeks of solution-focused group art therapy among female high-school students and conducted the PITR, along with a self-report regarding psychological inventory, as a pre-/post-test to verify the effectiveness of the therapy. The authors found that group art therapy was effective, and they observed changes in both the psychological and drawing tests. Specifically, the CCS increased significantly and the SS decreased significantly. Shin, Choi, and Kong (2011) examined the effects of supportive group art therapy on the stress and psychological exhaustion of civic activists and found similar PITR pre- and post-test results indicating group art therapy effectiveness. The CCS rose significantly and the SS decreased significantly. Taken together, these results confirm the importance of a comprehensive approach in psychological assessment using drawings.

The regression analysis conducted in this study proved that PITR can serve as a predictor of unit cohesion of conscript soldiers. It should be noted that other scores of the PITR were not included as a valid independent variable. In addition, the explanatory power of the RS was relatively low. These results imply that a conservative approach is needed in the use or interpretation of drawing test results. In other words, the application of the drawing test to predict soldiers' psychology should be approached with care. As drawing engages individuals' emotions, fantasies, and imaginations, it is still of great value in understanding people. However, drawings should only be used as supplementary material in predicting individuals' psychology such as unit cohesion.

Drawing tests have long been used for nonverbal assessments of psychological status. Unlike question-and-response tests, which require respondents to read, consider, and answer questions, drawing tests an individual's internal censorship and can facilitate non-defensive expression. Therefore, drawing tests complement verbal communication and are highly applicable in situations when risk 
should be preemptively distinguished, such as in education and clinical practice. Based on the results of this study, we expect that PITR will be used as an auxiliary tool to evaluate psychological aspects of soldiers in the future.

The limitations of this study and suggestions for subsequent research are as follows. First, the instructions used in this study were minimal and involved simply asking participants to draw a person in the rain. Furthermore, we did not specifically limit the drawing of stick figures. People unfamiliar with drawing tend to draw stick figures to represent people, and it is possible that these responses lowered the mean of the resource scale score which includes extracting the number of omitted body parts. Future researchers should consider indicating in the instructions whether to specifically prohibit stick figures. Second, for this study, we used size A4 paper, whereas Lack's evaluation manual was based on a letter-sized piece of paper. Although the difference in paper size is small, it might be necessary to classify results according to the size of the drawing paper.

\section{Acknowledgements}

This research was supported by the National Research Foundation of Korea (NRF) grant funded by the Korea government (MSIT) (2018RIA5A7025522).

\section{Conflicts of Interest}

The authors declare no conflicts of interest regarding the publication of this paper.

\section{References}

Ahn, H., Sohn, N., Lee, M., \& Seo, E. (2007). Military Adjustment among Korean Servicemen and Its Relation to Human Rights Violation Experiences. The Korea Journal of Counseling, 8, 425-435. https://doi.org/10.15703/kjc.8.2.200706.425

Carless, S. A., \& De Paola, C. (2000). The Measurement of Cohesion in Work Teams. Small Group Research, 31, 71-88. https://doi.org/10.1177/104649640003100104

Choi, Y., \& Kim, G. (2009). The Effects of Solution-Focused Art Therapy on Stress Coping Styles and Self-Esteem of High School Girls. Korean Journal of Art Therapy, 16, 655-678. https://doi.org/10.35594/kata.2009.16.4.007

Chun, S., Chae, S., \& Lee, J. (2016). The Moderating Effect of Social Support in the Relationship between Military Life Stress and Adjustment of Soldiers. The Journal of Humanities and Social Sciences, 17, 31-57. https://doi.org/10.15818/ihss.2016.17.2.31

Chung, K. (2012). “The Person in the Rain” Drawing Response Characteristics and Ways of Stress Coping in College Students. Korean Journal of Art Therapy, 19, 1029-1044. https://doi.org/10.35594/kata.2012.19.5.004

Hammer, E. F. (1958). The Clinical Application of Projective Drawings. Springfield, IL: Charles C Thomas.

Hong, J., \& Yang, N. (2013). An Effect of Soldier Stress on Suicidal Ideation: Self-Esteem, Alienation, Frustration Mediating Effect. Korean Journal of Counseling, 14, 1423-1441. https://doi.org/10.15703/kjc.14.2.201304.1423

Jeong, E., \& Kim, G. (2008). Relationship of Academic Stress in Middle School and PITR Responses. Journal of Korean Home Management Association, 26, 71-81. 
Jue, J., \& Ha, J. H. (2019a). A Study on Perceived Stress, Stress Response, and Mental Health Status According to the Characteristics of the Person-in-the-Rain Drawing Test Responses of the Army Soldiers. Korean Journal of Art Therapy, 26, 1119-1134.

Jue, J., \& Ha, J. H. (2019b). The Person-in-the-Rain Drawing Test as an Assessment of Soldiers' Army Life Adjustment and Resilience. Psychology, 10, 1418-1434. https://doi.org/10.4236/psych.2019.1011093

Jue, J., \& Kim, T. E. (2011). Female High School Students' Juvenile Delinquency and Anger in the Person in the Rain Test. Art Education Research Review, 25, 217-240.

Jung, W., \& Lee, C. (2008). A Study on the Predictive Factors of Desertion from the Military Services. Social Science Research, 17, 2-18.

Kang, H., \& Lee, K. (2014). A Study on the Response Characteristic of "Person in the Rain” Drawing Test Based on the Level of Job Stress of Elementary School Teacher. Korean Journal of Art Therapy, 21, 681-700. https://doi.org/10.35594/kata.2014.21.4.004

Kim, E. Y. (2009). A Study on New-Generation Soldiers' Adaptation to Their Military Life and Practice of the Military Social Welfare. Korean Academy of Military Social Welfare, 2, 67-108.

Kim, S.-B. (2011). The Study of "The Person in the Rain" Drawing Response Characteristics to Vocational High School Students' Stress. Unpublished Master's Thesis, Gyeongsangbuk-do: Daegu University.

Koo, S. (2013). Study for the Problem of Soldiers' Mental Health and the State of Military Counseling Service. Korean Journal of Counseling and Psychotherapy, 4, 1-20.

Krom, C. P. (2002). Hospice Nurses and the Palliative Care Environment: Indicators of Stress and Coping in the Draw-a-Person-in-the-Rain Test. Unpublished Master's Thesis, New Haven, CT: Albertus Magnus College.

Kwon, H. J., Kim, S. K., \& Song, D. H. (2016). The Characteristics of Responses to DAPR (Draw-a-Person-in-the-Rain) Assessment Based on the Level of Stress Response, Self-Efficacy of Nurses. The Journal of the Korean Association of Psychotherapy, 8, 81-111.

Lack, H. (1996). The Person-in-the-Rain Projective Drawing as a Measure of Children's Coping Capacity: A Concurrent Validity Study Using Rorschach, Psychiatric and Life History Variables. Unpublished Doctoral Dissertation, Fresno, CA: The California School of Professional Psychology.

Lee, D., Seo, H., \& Byun, S. (2016). A Study on Effectiveness the Army Soldiers of Military Life Stress, Suicidal Ideation of Adjustment to Military Life: Based on Mediating Effects of Social Support. Korean Academy of Military Social Welfare, 9, 5-31.

Lee, J. N. (2006). A Study of Organizational Citizenship Behavior Influenced by Both Group Cohesiveness and Job Characteristics. Unpublished Doctoral Dissertation, Chungcheongnam-do: Korea University of Technology Education.

Lee, J. Y., \& Park, Y. H. (2012). Soldier Stress and Health Promotion Behavior of Soldiers in Specific Environment (GOP, GP). Journal of Military Nursing Research, 30, 44-59.

Lee, S. H., \& Lee, K. M. (2014). A Study on the Relation between Response Characteristics in Person-in-the-Rain Drawing Test and Non-Commissioned Officers' Job Stress Level. Journal of Arts Psychotherapy, 10,39-62.

Oster, G., \& Gould, P. (1987). Using Drawing in Assessment and Therapy: A Guide for Mental Health Professionals. New York: Brunner/Mazel.

Rossi, A. (1997). The Draw-a-Person-in-the-Rain Technique: A Study to Determine Its Use as an Informative, Adjunct Assessment Tool for Direct Practice Social Workers. 
Unpublished Master's Thesis, New Haven, CT: Southern Connecticut State University.

Russo, A. (2007). The Draw-a-Person-in-the-Rain Technique to Assess Stress in Elementary School Professionals. Unpublished Master's Thesis, New Haven, CT: Albertus Magnus College.

Seol, J. (2018). The Role of Psychological Hardiness and Social Support between Stress and Mental Health among Military Personnel: A Mediated Moderation Analysis. The Korean Journal of Health Psychology, 23, 57-79. https://doi.org/10.17315/kjhp.2018.23.1.004

Shin, H., Choi, E., \& Kong, M. (2011). An Effect of Supportive Group art Therapy upon NGO Activist's Psychological Exhaustion. Korean Journal of Art Therapy, 18, 129-151. https://doi.org/10.35594/kata.2011.18.1.007

Siebold, G. L. (2007). The Essence of Military Group Cohesion. Armed Forces and Society, 33, 286-295. https://doi.org/10.1177/0095327X06294173

Son, M. (2004). The Study about Stress and Coping Behavior of Elementary School Students with PITR. Unpublished Doctoral Dissertation, Busan: Kyungsung University.

Son, M. (2007). Research on Measuring of Stress and Coping Behavior of Elementary Students through Drawing of People in the Rain (PITR). Korean Journal of Art Therapy, 14, 649-668. https://doi.org/10.35594/kata.2007.14.4.003

Verinis, J. S., Lichtenberg, E. F., \& Henrich, L. (1974). The Draw-a-Person in the Rain Technique: Its Relationship to Diagnostic Category and Other Personality Indicators. Journal of Clinical Psychology, 30, 407-414. https://doi.org/10.1002/1097-4679(197407)30:3<407::AID-JCLP2270300358>3.0.CO;2$\underline{6}$

Wang, T. G., Ying, T. C., Jiang, J. J., \& Klein, G. (2006). Group Cohesion in Organizational Innovation: An Empirical Examination of ERP Implementation. Information and Software Technology, 48, 235-244. https://doi.org/10.1016/j.infsof.2005.04.006

Williams, J., Brown, J. M., Bray, R., Goodell, E. M., Olmsted, K. R., \& Adler, A. B. (2016). Unit Cohesion, Resilience, and Mental Health of Soldiers in Basic Combat Training. Military Psychology, 28, 241-250. https://doi.org/10.1037/mil0000120

Willis, L. R., Joy, S. P., \& Kaiser, D. H. (2010). Draw-a-Person-in-the-Rain as an Assessment of Stress and Coping Resources. The Arts in Psychotherapy, 37, 233-239. https://doi.org/10.1016/j.aip.2010.04.009

Yang, W., \& Won, H. (2013). An Analysis of Correlation of High School Students' Stress from College-Bound Study, Depression, and Suicidal thoughts with Their Person-in-the-Rain Drawings. Korean Journal of Art Therapy, 20, 263-283.

https://doi.org/10.35594/kata.2013.20.2.002 